\title{
A new rapid colourimetric method for testing Mycobacterium tuberculosis susceptibility to isoniazid and rifampicin: a crystal violet decolourisation assay
}

\author{
Ahmet Yilmaz Coban/+ \\ Department of Medical Microbiology, Medical School, Ondokuz Mayis University, Samsun, Turkey
}

\begin{abstract}
The aim of this study was to investigate the performance of a new and accurate method for the detection of isoniazid (INH) and rifampicin (RIF) resistance among Mycobacterium tuberculosis isolates using a crystal violet decolourisation assay (CVDA). Fifty-five M. tuberculosis isolates obtained from culture stocks stored at $-80^{\circ} \mathrm{C}$ were tested. After bacterial inoculation, the samples were incubated at $37^{\circ} \mathrm{C}$ for seven days and $100 \mu \mathrm{L}$ of CV $(25 \mathrm{mg} / \mathrm{L}$ stock solution) was then added to the control and sample tubes. The tubes were incubated for an additional 24-48 h. CV (blue/purple) was decolourised in the presence of bacterial growth; thus, if CV lost its colour in a sample containing a drug, the tested isolate was reported as resistant. The sensitivity, specificity, positive predictive value, negative predictive value and agreement for INH were 92.5\%, 96.4\%, 96.1\%, 93.1\% and 94.5\%, respectively, and $88.8 \%, 100 \%, 100 \%, 94.8 \%$ and $96.3 \%$, respectively, for RIF. The results were obtained within eight-nine days. This study shows that CVDA is an effective method to detect $\mathrm{M}$. tuberculosis resistance to INH and RIF in developing countries. This method is rapid, simple and inexpensive. Nonetheless, further studies are necessary before routine laboratory implementation.
\end{abstract}

Key words: Mycobacterium tuberculosis - multidrug resistance - susceptibility testing - isoniazid - rifampicin - crystal violet decolourisation assay

Tuberculosis is a major public health problem, particularly in developing countries. Mycobacterium tuberculosis isolates that are resistant to at least rifampicin (RIF) and isoniazid (INH) are defined as multidrug resistant (MDR). As drug resistance is a serious problem for control programmes, there is a need for new, rapid and accurate drug susceptibility tests for the diagnosis of MDR tuberculosis isolates (Martin et al. 2007). Indeed, the early detection of drug resistance in M. tuberculosis isolates allows for the use of appropriate antibiotics for the treatment of patients, which is the most important step for controlling this disease (Martin et al. 2008). The proportion method, the absolute concentration method, the resistance ratio method and the non-radiometric MGIT 960 system (Becton \& Dickinson Diagnostic Systems, Sparks, MD, USA) are prevalent conventional methods for drug susceptibility testing (Kent \& Kubica 1985, Martin et al. 2007, CLSI 2011). However, obtaining drug susceptibility results on Löwenstein-Jensen (LJ) and agarbased media requires at least three-six weeks. Although the commercial liquid-based BACTEC 460 TB system is faster, it nevertheless requires special equipment, contains radioactive material and is expensive; furthermore, the use of this method is difficult in many countries. The BACTEC MGIT 960 system (Becton \& Dickinson) is a

doi: 10.1590/0074-0276140297

+ Corresponding author: cobanay2003@gmail.com

Received 4 June 2013

Accepted 7 October 2013 non-radiometric method, but has a high cost, which is the main disadvantage (Martin et al. 2007).

Recently, inexpensive, rapid and reliable colourimetric methods have attracted increased interest; of these, the resazurin microplate method and the nitrate reductase assay are the most popular (Angeby et al. 2002, Palomino et al. 2002, Syre et al. 2003, Coban et al. 2004, Martin et al. 2005, Montoro et al. 2005, Bwanga et al. 2010, Dixit et al. 2012). Crystal violet (CV) is a triphenylmethane dye that is antimicrobial and toxic to mammalian cells. CV is used for the prevention of fungal growth in poultry feed; however, in contrast to bacteria and fungi, mycobacteria are considered to be resistant to $\mathrm{CV}$. It has been suggested that this resistance to $\mathrm{CV}$ could be the result of the reduction of $\mathrm{CV}$ and sequestration in the lipid fraction of these bacteria. CV can be reductively decolourised and it has also been shown that water-borne pathogenic mycobacteria decolourise CV (Jones \& Falkinham III 2003).

Accordingly, I have developed a new method for the detection of INH and RIF resistance in M. tuberculosis isolates using a CV decolourisation assay (CVDA).

\section{MATERIALS AND METHODS}

Bacterial isolates - Fifty-five M. tuberculosis isolates obtained from culture stocks at $-80^{\circ} \mathrm{C}$ were tested by CVDA. All isolates were freshly grown on LJ media. Eighteen were MDR isolates, nine isolates were only resistant to INH and the remaining 28 were sensitive to both INH and RIF. In the present study, H37Rv-ATCC 25618 (susceptible to all drugs), ATCC 35822 (resistant to INH) and ATCC 35838 (resistant to RIF) were used as the control strains. 
The BACTEC 460 TB system (Becton \& Dickinson) was used as the reference method for the determination of susceptibility in the $18 \mathrm{MDR}$ isolates, whereas the BACTEC MGIT 960 system (Becton \& Dickinson) was used as the reference method for the determination of susceptibility in the remaining isolates.

Preparation of antibiotics and $\mathrm{CV}$ - INH, RIF and $\mathrm{CV}$ were purchased from Sigma. Stock solutions of INH and RIF at $1,000 \mathrm{mg} / \mathrm{L}$ were prepared in sterile distilled water and methanol, respectively, and the stock solutions were stored at $-20^{\circ} \mathrm{C}$ until use. Stock solutions of $\mathrm{CV}$ at $25 \mathrm{mg} / \mathrm{L}$ were prepared with sterile distilled water, sterilised by filtration and stored at $4^{\circ} \mathrm{C}$ until use.

Preparation of bacterial inocula - Five or six colonies of each the 55 isolates freshly grown on LJ media was suspended in a physiological saline tube containing 10-15 glass beads and then vortexed for $30 \mathrm{sec}$. The tube was kept in a vertical position for $1 \mathrm{~h}$ at room temperature to allow for the sedimentation of aerosols and large particles. The turbidity of the supernatant was adjusted to a McFarland standard of 1 (CLSI 2011).

Preparation of the medium - The bacteria were tested in Middlebrook $7 \mathrm{H} 9 \mathrm{~S}$ broth (containing $0.1 \%$ casiton, $0.5 \%$ glycerol and $10 \%$ oleic acid, albumin, dextrose and catalase). INH and RIF were tested at critical concentrations of $0.25 \mathrm{mg} / \mathrm{L}$ and $0.5 \mathrm{mg} / \mathrm{L}$, respectively (Martin et al. 2011). The test was performed in three tubes, including two assay tubes and one growth control tube. The assay tubes contained INH or RIF and the growth control tube was without antibiotics.

Determination of the $C V$ concentration - In this study, the concentration of CV was determined according to the value of tolerance described by Jones and Falkinham III (2003). The appropriate test concentration of $\mathrm{CV}$ was determined by titration of the stock solution. The most suitable concentration was $100 \mu \mathrm{L}$ of $25 \mathrm{mg} / \mathrm{L}$ a stock solution in a 1-mL tube.

Application of the test - An INH test tube $(0.25 \mathrm{mg} / \mathrm{L})$, an RIF test tube $(0.5 \mathrm{mg} / \mathrm{L})$ and an antibiotic-free growth control tube were used for each bacterium. A bacterial suspension $(50 \mu \mathrm{L})$ that was adjusted to McFarland standard 1 was inoculated into the three tubes and the tubes were incubated at $37^{\circ} \mathrm{C}$. On the seventh day of incubation, $100 \mu \mathrm{L}$ of $\mathrm{CV}(25 \mathrm{mg} / \mathrm{L}$ stock solution) was then added to the tubes and incubated for an additional 24-48 h. As CV (blue/purple) is decolourised by the growth of bacteria, the isolate was considered to be resistant to that drug if the colour of CV was lost (Figs 1-3).

\section{RESULTS}

The sensitivity, specificity, positive predictive value (PPV), negative predictive value (NPV) and agreement for INH were found to be $92.5 \%, 96.4 \%, 96.1 \%, 93.1 \%$ and $94.5 \%$, respectively. Two isolates were found to be sensitive to INH by CVDA, though they were resistant according to the reference method. One INH-susceptible isolate was also found to be resistant by CVDA. The sensitivity, specificity, PPV, NPV and agreement for RIF were $88.8 \%, 100 \%, 100 \%, 94.8 \%$ and $96.3 \%$,

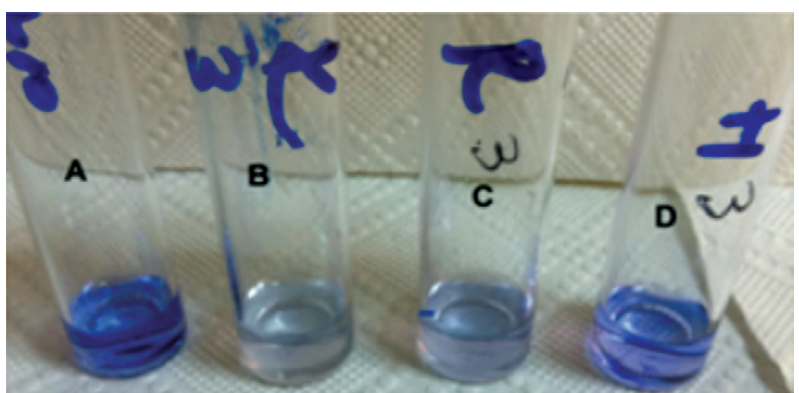

Fig. 1: blue/purple colour - there is no any bacterial growth. Decolourisation - there is bacterial growth. ATCC 35838 - rifampicin (RIF)-resistant standard strain. A: negative control tube without drug or bacteria; B: positive control tube with bacteria without drug; C: test tube with RIF (resistant to RIF); D: test tube with isoniazid (INH) (susceptible to INH).

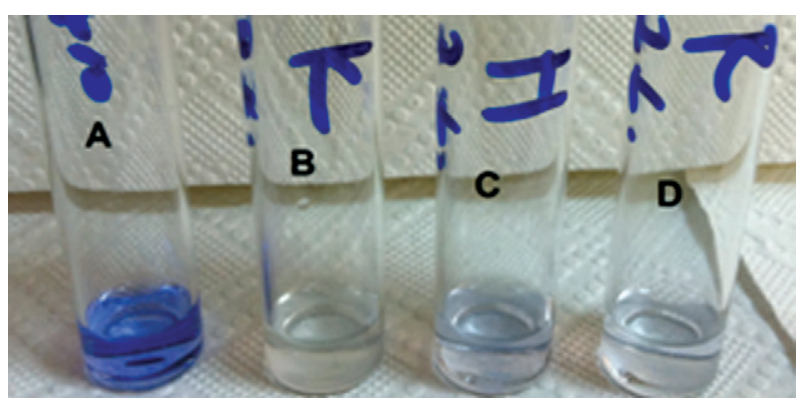

Fig. 2: blue/purple colour - there is no any bacterial growth. Decolourisation - there is bacterial growth. A clinical multidrug resistant isolate - resistant to isoniazid (INH) and rifampicin (RIF). A: negative control tube without drug or bacteria; B: positive control tube with bacteria without drug; C: test tube with INH (resistant to INH); D: test tube with RIF (resistant to RIF).

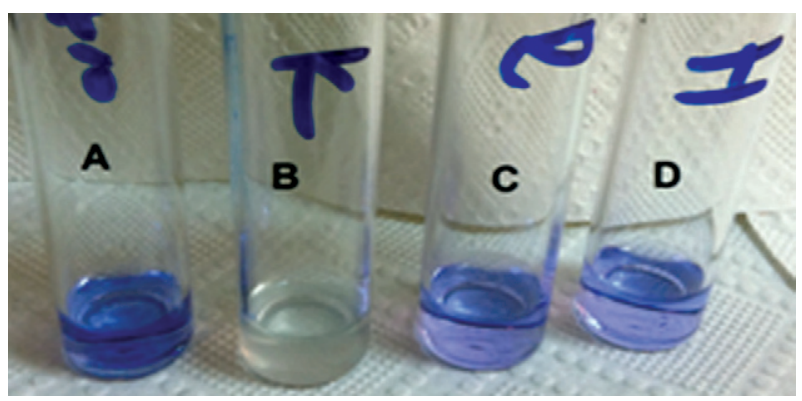

Fig. 3: blue/purple colour - there is no any bacterial growth. Decolourisation - there is bacterial growth. A clinical isolate - susceptible to to isoniazid (INH) and rifampicin (RIF). A: negative control tube without drug or bacteria; B: positive control tube with bacteria without drug; C: test tube with RIF (susceptible to RIF); D: test tube with INH (susceptible to INH).

respectively. Two RIF-resistant isolates were found to be susceptible by CVDA (Table). The results were obtained within eight-nine days. 
TABLE

Comparing the results of crystal violet decolourisation assay (CVDA) with those obtained with reference method

\begin{tabular}{|c|c|c|c|c|c|c|c|c|}
\hline \multirow[b]{2}{*}{ Drug } & \multirow[b]{2}{*}{ CVDA } & \multicolumn{2}{|c|}{$\begin{array}{l}\text { Reference method } \\
\text { 460TB/MGIT }\end{array}$} & \multirow{2}{*}{$\begin{array}{c}\text { Sensitivity } \\
(\%)\end{array}$} & \multirow{2}{*}{$\begin{array}{l}\text { Specificity } \\
(\%)\end{array}$} & \multirow{2}{*}{$\begin{array}{r}\text { PPV } \\
(\%)\end{array}$} & \multirow{2}{*}{$\begin{array}{l}\text { NPV } \\
(\%)\end{array}$} & \multirow{2}{*}{$\begin{array}{l}\text { Agreement } \\
(\%)\end{array}$} \\
\hline & & $\mathrm{R}$ & $\mathrm{S}$ & & & & & \\
\hline \multirow[t]{2}{*}{ INH } & $\mathrm{R}$ & $18 / 7$ & $0 / 1$ & 92.5 & 96.4 & 96.1 & 93.1 & 94.5 \\
\hline & $\mathrm{S}$ & $0 / 2$ & 27 & - & - & - & - & - \\
\hline \multirow[t]{2}{*}{ RIF } & $\mathrm{R}$ & $16 / 0$ & $0 / 0$ & 88.8 & 100 & 100 & 94.8 & 96.3 \\
\hline & $\mathrm{S}$ & $2 / 0$ & $0 / 37$ & - & - & - & - & - \\
\hline
\end{tabular}

a: automated systems included BACTEC 460 TB and MGIT 960 were used as reference methods; INH: isoniazid; NPV: negative predictive value; PPV: positive predictive value; R: resistant; RIF: rifampicin; S: sensitive.

\section{DISCUSSION}

There is increasing interest in the use of colourimetric methods for the susceptibility testing of $M$. tuberculosis isolates. These methods have certain advantages in that they are easy to perform, reproducible, reliable and readily available and have a very low cost. The present study is the first to assess $\mathrm{CV}$ decolourisation for the evaluation of $M$. tuberculosis antimicrobial susceptibility.

Jones and Falkinham III (2003) showed that CV and malachite green were decolourised by water-borne pathogenic mycobacteria, a feature that is believed to be due to the properties of the bacterial cell wall. It was suggested that decolourisation could be due to the reduction of $\mathrm{CV}$ and its sequestration in the lipid fraction. In that same study, water-related mycobacterial pathogens were shown to be tolerant to $\mathrm{CV}$ concentrations of up to 15 mg/L (Jones \& Falkinham III 2003). Therefore, a concentration of less than $15 \mathrm{mg} / \mathrm{L}$ was used in the present study. As a result of titration, $100 \mu \mathrm{L}$ of a $25 \mathrm{mg} / \mathrm{L}$ stock solution of $\mathrm{CV}$ was added to the assay tubes; thus, the final concentration would be $2.5 \mathrm{mg} / \mathrm{L}$, which the bacteria may be able to tolerate.

Colourimetric methods, such as the resazurin microplate method, the nitrate reductase assay (NRA), (2-methoxy-4-nitro-5-sulphophenyl)-2H-tetrazolium-5carboxanilide, 2,3-bis (2-methoxy-4-nitro-5-sulfophenyl)5-[(phenylamino) carbonyl]-2H-tetrazolium hydroxide and the malachite green decolourisation assay, have been developed for the drug susceptibility testing of $M$. tuberculosis clinical isolates and these new colourimetric methods have yielded concordant results with reference methods (Angeby et al. 2002, Palomino et al. 2002, de Logu et al. 2003, Syre et al. 2003, Coban et al. 2004, Martin et al. 2005, Montoro et al. 2005, Farnia et al. 2008, Bwanga et al. 2010, Dixit et al. 2012). NRA requires three different compounds, including sulfanilamide, n-1-naphthylethylenediamine and concentrated hydrochloric acid for the Griess reagent; in addition, freshly prepared Griess reagent should be used for the test. The resazurin microplate method requires resazurin salt powder. In contrast, CV dye is inexpensive and is used for Gram staining in clinical microbiology laboratories; therefore, it can be easily obtained by many laboratories.
In this study, the critical concentration used was 0.5 $\mathrm{mg} / \mathrm{L}$ for RIF and the results from two isolates were inconsistent with the reference method: these isolates were sensitive according to CVDA, but were resistant with the reference method. However, full agreement may be observed if the critical concentration is reduced by one or two dilutions. This new colourimetric method showed sensitivities, specificities and agreements of $92.5 \%, 88.8 \%$ and $96.4 \%$ and $100 \%, 94.5 \%$ and $96.3 \%$, respectively, for INH and RIF. However, the low number of tested resistant strains may have resulted in the low sensitivity of the test. For this reason, further studies with more resistant strains are needed before routine laboratory implementation.

In conclusion, a new method based on CV decolourisation was developed. Based on the accuracy reported here, CVDA is a rapid, simple, inexpensive and potent method for the detection of INH and RIF resistance in M. tuberculosis isolates, particularly in developing countries.

\section{REFERENCES}

Angeby KAK, Klintz L, Hoffner SE 2002. Rapid and inexpensive drug susceptibility testing of Mycobacterium tuberculosis with a nitrate reductase assay. J Clin Microbiol 40: 553-555.

Bwanga F, Joloba ML, Haile M, Hoffner S 2010. Evaluation of seven tests for the rapid detection of multidrug-resistant tuberculosis in Uganda. Int J Tuberc Lung Dis 14: 890-895.

CLSI - Clinical and Laboratory Standards Institute 2011. Susceptibility testing of mycobacteria, Nocardia and other aerobic actinomycetes. Approved Standard M24-A2, 2nd ed., CLSI, Wayne, 14 pp.

Coban AY, Birinci A, Ekinci B, Durupinar B 2004. Drug susceptibility testing of Mycobacterium tuberculosis with nitrate reductase assay. Int J Antimicrob Agents 24: 304-306.

de Logu A, Pellerano ML, Sanna A, Pusceddu MC, Uda P, Saddi B 2003. Comparison of the susceptibility testing of clinical isolates of Mycobacterium tuberculosis by the XTT colorimetric method and the NCCLS standards method. Int J Antimicrob Agents 21: 244-250.

Dixit P, Singh U, Sharma P, Jain A 2012. Evaluation of nitrate reduction assay, resazurin microtiter assay and microscopic observation drug susceptibility assay for first line antitubercular drug susceptibility testing of clinical isolates of M. tuberculosis. J Microbiol Methods 88: 122-126. 
Farnia P, Masjedi MR, Mohammadi F, Tabarsei P, Farnia P, Mohammadzadeh AR, Baghei P, Varahram M, Hoffner S, Velayati AA 2008. Colorimetric detection of multidrug-resistant or extensively drug-resistant tuberculosis by use of malachite green indicator dye. J Clin Microbiol 46: 796-799.

Jones JJ, Falkinham III JO 2003. Decolorization of malachite green and crystal violet by waterborne pathogenic mycobacteria. Antimicrob Agents Chemother 47: 2323-2326.

Kent PT, Kubica GP 1985. Public health mycobacteriology: a guide for the level III laboratory, US Department of Health and Human Services, Atlanta, $207 \mathrm{pp}$.

Martin A, Montoro E, Lemus D, Simboli N, Morcillo N, Velasco M, Chauca J, Barrera L, Ritacco V, Portaels F, Palomino JC 2005. Multicenter evaluation of the nitrate reductase assay for drug resistance detection of Mycobacterium tuberculosis. J Microbiol Methods 63: 145-150.

Martin A, Paasch F, Docx S, Fissette K, Imperiale B, Ribón W, González LA, Werngren J, Engström A, Skenders G, Juréen P, Hoffner S, del Portillo P, Morcillo N, Palomino JC 2011. Multicentre laboratory validation of the colorimetric redox indicator (CRI) assay for the rapid detection of extensively drug-resistant (XDR) Mycobacterium tuberculosis. J Antimicrob Chemother 66: 827-833.
Martin A, Panaiotov S, Portaels F, Hoffner S, Palomino JC, Angeby $\mathrm{K} 2008$. The nitrate reductase assay for the rapid detection of isoniazid and rifampicin resistance in Mycobacterium tuberculosis: a systematic review and meta-analysis. $J$ Antimicrob Chemother 62: 56-64.

Martin A, Portaels F, Palomino JC 2007. Colorimetric redox-indicator methods for the rapid detection of multidrug resistance in Mycobacterium tuberculosis: a systematic review and meta-analysis. J Antimicrob Chemother 59: 175-183.

Montoro E, Lemus D, Echemendia M, Martin A, Portaels F, Palomino JC 2005. Comparative evaluation of the nitrate reductase assay, the MTT test and the resazurin microtiter assay for drug susceptibility testing of clinical isolates of Mycobacterium tuberculosis. J Antimicrob Chemother 55: 500-505.

Palomino JC, Martin A, Camacho M, Guerra H, Swings J, Portaels F 2002. Resazurin microtiter assay plate: simple and inexpensive method for detection of drug resistance in Mycobacterium tuberculosis. Antimicrob Agents Chemother 46: 2720-2722.

Syre H, Phyu S, Sandven P, Bjorvatn B, Grewal HM 2003. Rapid colorimetric method for testing susceptibility of Mycobacterium tuberculosis to isoniazid and rifampin in liquid cultures. J Clin Microbiol 41: 5173-5177. 